\title{
Endocarditis marántica con embolia sistémica como manifestación de adenocarcinoma papilar de pulmón
}

\author{
Martha A. Casallas-Rivera ${ }^{11,3}$, Carolinie Gómez-Torres 2,3 \\ 1. Especialista en medicina interna, Docente Universidad de La Sabana, Grupo de investigación Riesgo Cardiovascular, \\ Trombosis y Anticoagulación (RICAVTA). Bogotá, Colombia. \\ 2. Residente de medicina interna, Universidad de La Sabana, Chía, Colombia. \\ 3. Servicio de medicina interna, Hospital Universitario de La Samaritana, Bogotá, Colombia. \\ Conflicto de interés: Declaramos no tener conflicto de interés. \\ Financiación: Esta publicación fue financiada por los autores.
}

Se presenta el caso de un hombre de 61 años, portador de un cáncer pulmonar en quien lesiones de aspecto embólico llevan al diagnóstico de Endocarditis marántica (no infecciosa). Se describen las características clínicas del paciente, los métodos diagnósticos incluyendo imágenes ecocardiográficas y la confirmación necrópsica.

\section{Nonbacterial thrombotic endocarditis with systemic embolism as a manifestation of papillary lung adenocarcinoma}

A 61-year-old male with skin lesions suggesting embolic phenomena, was thoroughly investigated and a final diagnosis of marantic (non-infectious) endocarditis was established. Clinical characteristics and diagnostic investigation through laboratory test and images sustained the diagnosis. The use of transesophageal echocardiography is emphasized. This was finally confirmed by findings at necropsy.

\section{Correspondencia:}

Dra. Martha Alejandra Casallas Rivera,

Servicio de Medicina Interna, Hospital

Universitario de La Samaritana,

Bogotá, D.C., Colombia.

m_aleja99@hotmail.com 


\section{Introducción:}

La endocarditis trombótica no bacteriana (ETNB) o endocarditis marántica, término introducido por primera vez por Gross y Friedberg en $1936^{1}$, se caracteriza por el depósito de trombos de plaquetas y fibrina estériles sobre válvulas cardíacas usualmente sin reacción inflamatoria $^{2}$. Estas lesiones van desde agregados microscópicos de plaquetas a vegetaciones en las válvulas del corazón (más frecuente aórtica y mitral) en ausencia de bacterie$\mathrm{mia}^{2}$. El mecanismo fisiopatológico no es claro, siendo el factor más importante un estado de hipercoagulabilidad generado principalmente por neoplasias avanzadas, tales como carcinoma renal y adenocarcinoma productor de mucina (de páncreas, estómago, vesícula biliar, conductos biliares, ovario, pulmón, próstata, mama, colon $)^{2,3}$. En el cáncer los altos niveles de factor de necrosis tumoral e interleuquina-1 que se presentan pueden causar daño en el endotelio de la válvula y formación de trombos ${ }^{3}$.

También puede complicar enfermedades autoinmunes, como lupus eritematoso sistémico (LES), síndrome de anticuerpos antifosfolípidos y artritis reumatoidea (en válvulas ya con daño inmunológico y una mayor respuesta inflamatoria); valvulopatía reumática $2,3,4,5$ y procesos agudos como sepsis, infecciones (como neumonía, pielonefritis y tuberculosis) o quemaduras extensas ${ }^{2,3}$.

El diagnóstico diferencial comprende la enfermedad valvular reumática, la endocarditis infecciosa (EI) y la endocarditis de Libman-Sacks frecuentemente asociada a LES ${ }^{6}$.

Teniendo en cuenta la baja incidencia de esta entidad ( $1.08 \%$ en una serie de 2041 necropsias de adultos) $)^{2}$ y la baja frecuencia con la que el diagnóstico de ETNB precede al de la enfermedad maligna, realizamos este reporte de caso.

\section{Caso clínico:}

Hombre de 61 años de edad con antecedentes de hipertensión arterial y enfermedad pulmonar obstructiva crónica secundaria a tabaquismo pesado (Índice Paquete/Año: 45 , suspendido 5 años atrás); desde hace cuatro meses anticoagulado por tromboembolia pulmonar, trombosis venosa profunda poplítea bilateral y del confluente yugulo subclavio, lo cual se manifestó como aumento progresivo de disnea, lesiones violáceas en pulpejos de manos y pies, dolor articular y en la planta de los pies que limitaba la marcha. Ingresó por cuadro clínico de 1 mes de evolución de sensación vertiginosa asociada a cefalea frontal y astenia, persistencia de lesiones violáceas en pulpejos de manos y pies y postración. Siete días previos a su ingreso presentó somnolencia, desorientación, lenguaje incoherente y conducta agresiva.

Al ingreso se encontraba con oxígeno por cánula nasal, taquicárdico, con adenomegalias cervicales bilaterales, soplo sistólico grado I en foco mitral, sinovitis en articulaciones metacarpofalángicas, metatarsianas, codo y hombro derecho, equimosis en antebrazos, lesiones purpúricas en pulpejos de pies y manos (lesiones de Janeway), piernas y antebrazos (Figura 1 y 2) y cianosis distal. Estaba somnoliento, hipoproséxico, bradipsíquico, desorientado en las 3 esferas, no colaborador para campimetría, con fundoscopia normal, fuerza $4 / 5$ en las cuatro extremidades, hipotrofia generalizada predominante en interóseos bilateral.

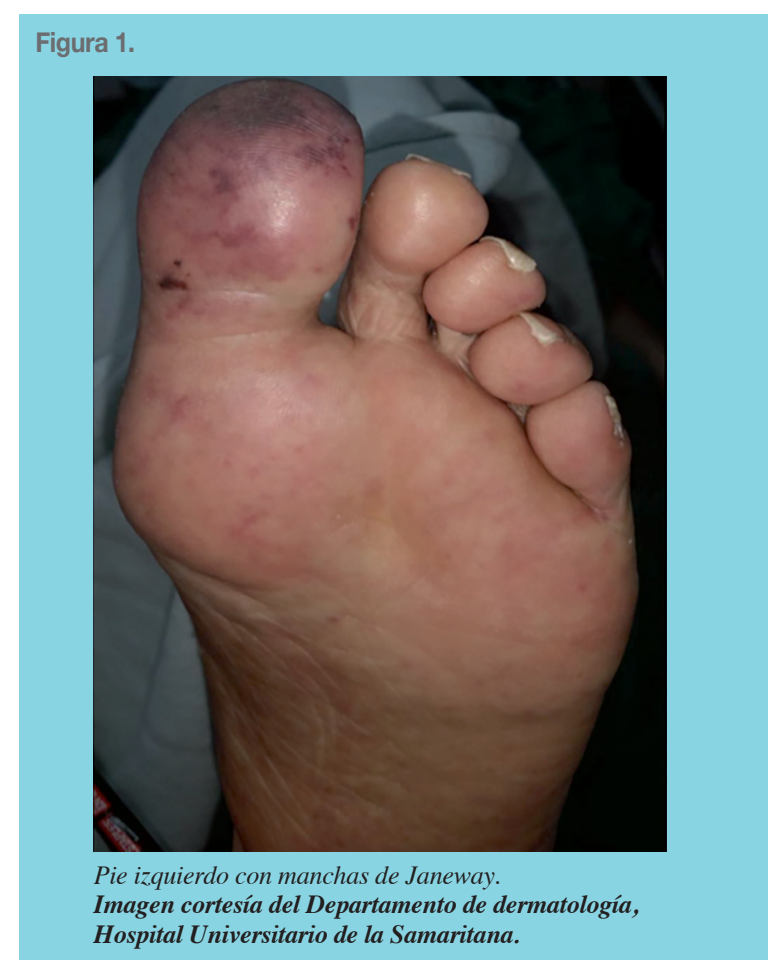

Figura 2.

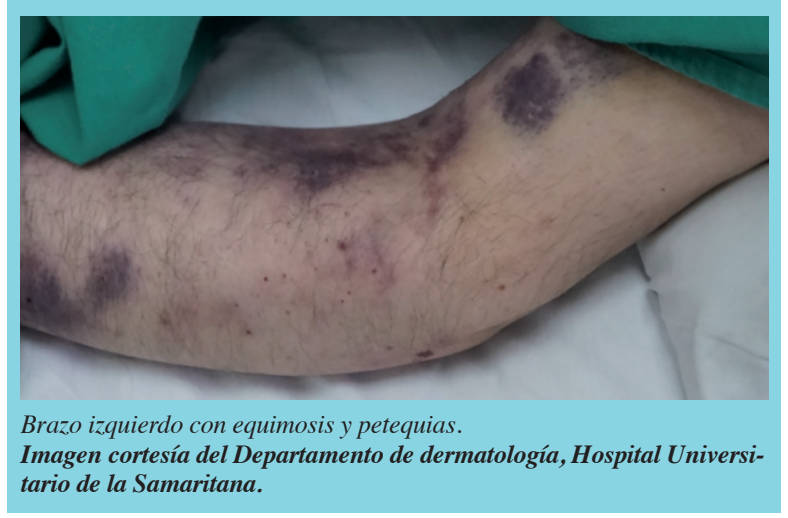


Una resonancia magnética (IRM) cerebral mostró áreas hipointensas subagudas en el lóbulo parietal derecho, frontal y occipital izquierdo, este último con colección hemorrágica intraparenquimatosa (Figura 3).

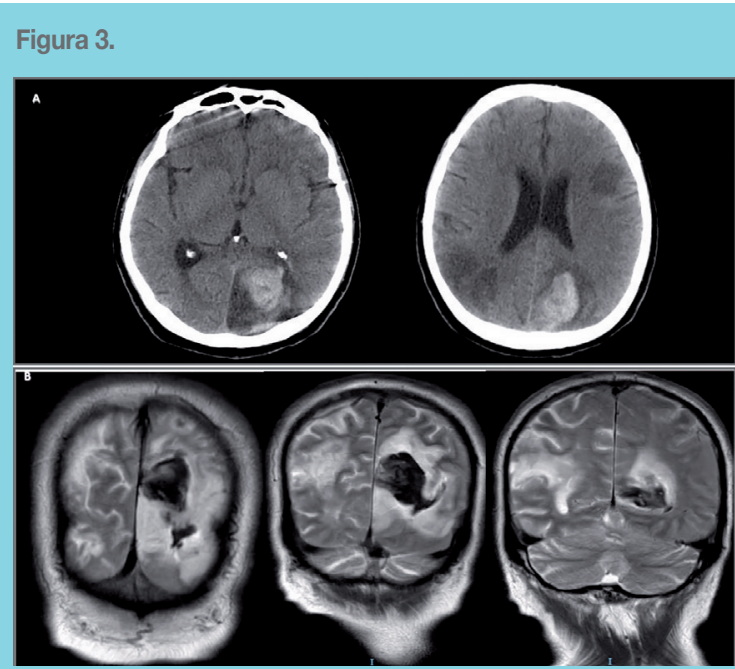

A. TAC cerebral simple. Corte axial. Lesiones isquémicas en territorio posterior bilateral del lado izquierdo con transformación hemorrágica y ligero efecto de masa sobre el cuerno occipital del ventrículo lateral. Lesión subcortical en región frontal del lado izquierdo y en menor grado en la región frontal derecha. B. RMN Cerebral simple. Corte coronal. Areas de isquemia que comprometen los giros frontales medios, lóbulo parietal derecho y colección hemorrágica parenquimatoso en el polo occipital izquierdo, con edema perilesional y signos de extensión de la colección hemorrágica hacia el asta occipital homolateral, moderado efecto de masa. Imágenes cortesía del departamento de Radiología, Hospital Universitario de la Samaritana.

Los antecedentes sugerían hipercoagulabilidad que, asociado a trombocitopenia y esquistocitos reportados al ingreso, más los hallazgos del examen físico y de las imágenes cerebrales, hicieron sospechar una tormenta trombótica probablemente en relación con un síndrome
Figura 5.

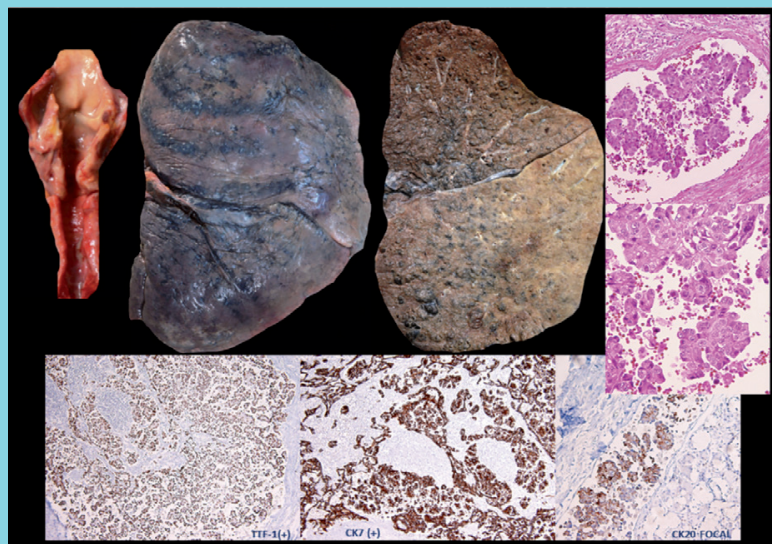

Pulmón izquierdo. Peso 900 g. Evidencia enfisema y bulas e infiltración por adenocarcinoma papilar moderadamente diferenciado.

Imágenes cortesía del Departamento de patología, Hospital Universitario de la Samaritana.

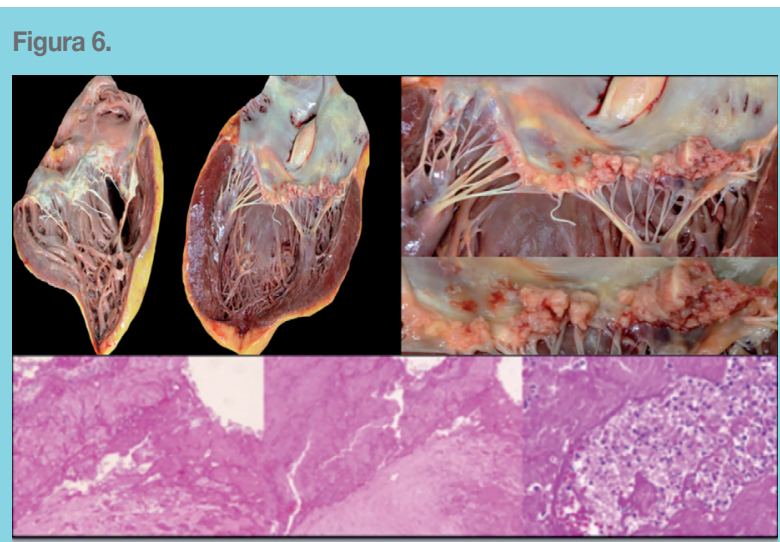

Válvula mitral con endocarditis verrugosa extensa.

Imágenes cortesía del Departamento de patología, Hospital Universitario de la Samaritana.

\section{Figura 4.}
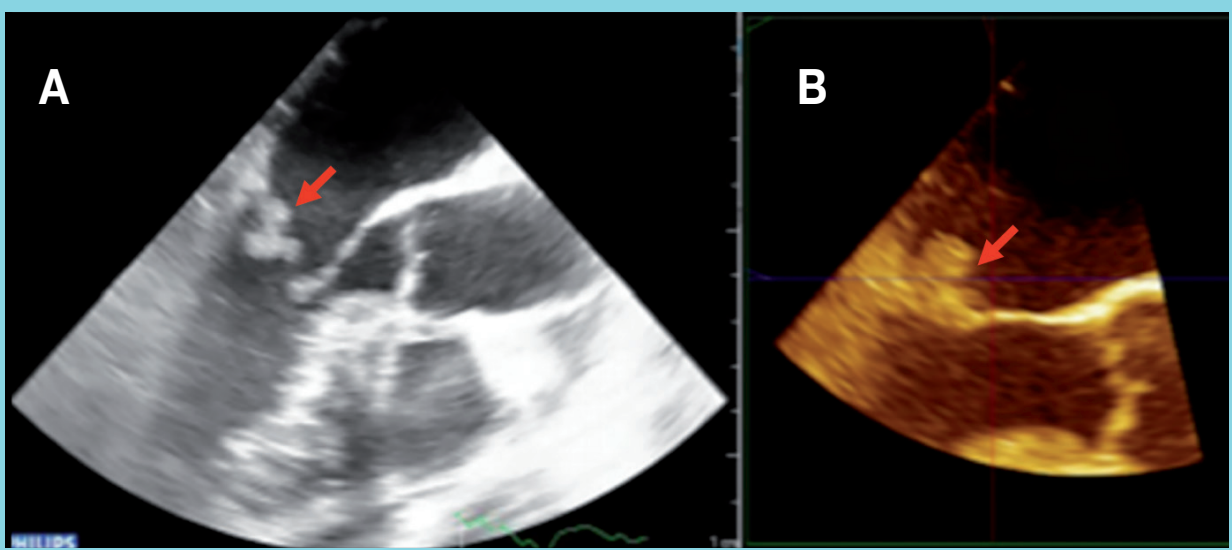

Ecocardiograma transesofágico - En la valva posterior de la válvula mitral, cara auricular y hacia el extremo medial, hay una imagen de aspecto más o meno pediculado de ecogenicidad intermedia, móvil, de mayor diámetro medido $0.9 \mathrm{~cm}$ que puede corresponder a vegetación y menos probable a masa o trombo (A. Vista $2 D$, medio-esofágico en un eje largo del corazón , B. Vista previa con zoom). Imágenes cortesía del departamento de Cardiología, Hospital Universitario de la Samaritana. 
de anticuerpos antifosfolípidos versus microangiopatía trombótica o vasculitis sistémica. Sin embargo, los estudios posteriores descartaron estas entidades.

La clínica indicaba embolias sistémicas por lo que se realizó ecocardiograma transesofágico que evidenció lesión pediculada a nivel de la valva posterior mitral de $0,9 \mathrm{~cm}$ (no identificada en el ecocardiograma transtorácico de ingreso) (Figura 4), con reactantes de fase aguda negativos, sin fiebre, sumado a hemocultivos y urocultivo negativos; considerando baja probabilidad de proceso infeccioso y quedando como opción una ETNB. Se consideró la anticoagulación, pero por el alto riesgo de aumento del sangrado intracerebral que presentaba esta se pospuso.

Una Tomografía Axial Computarizada (TAC) de tórax y abdomen contrastados no mostró signos de malignidad, pero sí engrosamiento pleural segmentario e infartos renales bilaterales.

El paciente presentó deterioro del patrón respiratorio con insuficiencia respiratoria sin respuesta al manejo y falleció antes de que se estableciera el diagnóstico etiológico. La necropsia reportó adenocarcinoma papilar moderadamente diferenciado de pulmón (Figura 5) con metástasis a ganglios linfáticos cervicales, tiroides, glándulas suprarrenales, riñón, bazo y páncreas, así como presencia de vegetaciones verrugosas en válvula mitral (Figura 6) y hemorragia extensa con trombo en lóbulo occipital iz-

\section{Figura 7.}

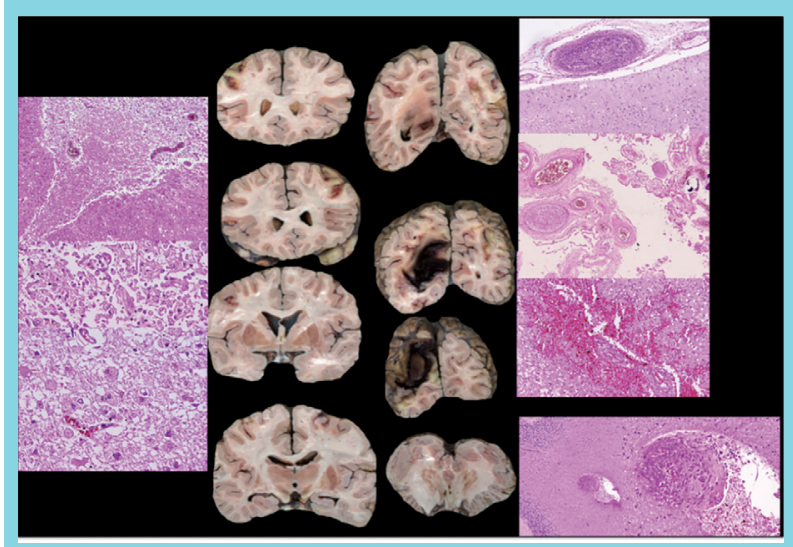

Cerebro, cortes coronales. Evidencia de hemorragia masiva en lóbulo occipital izquierdo con trombo.

Imágenes cortesía del Departamento de patología, Hospital Universitario de la Samaritana. quierdo (Figura 7).

\section{Discusión:}

La ETNB afecta principalmente a pacientes entre la cuarta y la octava década de la vida ${ }^{3}$ Las principales manifestaciones clínicas resultan de la embolia sistémica en lugar de la disfunción valvular ${ }^{3}$. Estas vegetaciones se desprenden fácilmente porque hay poca reacción inflamatoria en el sitio de unión ${ }^{2,3}$. Puede presentarse como infartos renales, esplénicos y hemorragias en astillas en las extremidades ${ }^{4}$. La morbilidad surge en los émbolos que avanzan al cerebro ${ }^{3}$ y la mortalidad está asociada al avanzado estado de la neoplasia de base.

El diagnóstico se dificulta por un bajo índice de sospecha y la baja sensibilidad de la ecocardiografía transtorácica, ya que esta no alcanza a evidenciar lesiones/ vegetaciones menores a $4 \mathrm{~mm}$ de diámetro ${ }^{2,3}$. No hay datos clínicos o métodos diagnósticos que permitan diferenciar una ETNB de una EI. Se debe sospechar cuando todas las pruebas microbiológicas son negativas; el estudio histopatológico logra discriminar entre una vegetación estéril o infectada; sin embargo, no se puede excluir la presencia de infección por microorganismos de cultivo exigente y de crecimiento lento como son los pertenecientes al grupo HACEK, bacterias intracelulares y hongos o por historia de terapia antibiótica previa ${ }^{7}$.

Su tratamiento se basa en el control de la enfermedad subyacente. Se sugiere la anticoagulación con heparina para prevenir las embolias, aunque no hay suficiente evidencia $^{2,4}$.

En este caso clínico, la ausencia de signos de infección y el no aislamiento microbiológico en presencia de vegetaciones en la válvula mitral, con lesión multiorgánica por embolia sistémica, nos orientó al diagnóstico de ETNB. El adenocarcinoma papilar de pulmón metastásico explicó el estado de hipercoagulabilidad, siendo la ETNB su manifestación.

Teniendo en cuenta que la ETNB es una entidad poco frecuente pero devastadora, debemos aumentar el grado de sospecha para lograr un diagnóstico temprano e iniciar un tratamiento dirigido. Debemos recordar que si el ecocardiograma transtorácico es normal, pero existe una alta sospecha, debe complementarse el estudio con un ecocardiograma transesofágico. 


\section{Referencias}

1. GROSS L Y FRIEDBERG CK. Nonbacterial thrombotic endocarditis. Classification and general description. Arch Intern Med (Chic). 1936;58:620-640.

2. LLENAS-GARCÍA J, GUERRA-VALESA JM, MONTES-MORENO S, LÓPEZ-RÍOS F, CASTELBÓN-FERNÁNDEZ FJ Y CHIMENO-GARCÍA J. Endocarditis trombótica no bacteriana: estudio clínico-patológico de una serie necrópsica. Rev Esp Cardiol. 2007; 60(5):493-5003. SALINAS A, BUSTAMANTE L, LANAS F, SOTO A, GARCÍA M, BARTOLOTTI C. Endocarditis marántica como presentación de cáncer de páncreas. Rev Med Chile 2017; 145: 1353-1358.

4. ZYLBERMAN M, DÍAZ COUSELO FA, SÁNCHEZ F, SAN-
TOS D, NERVO A. Endocarditis trombótica no bacteriana bivalvular asociada a cáncer y ecocardiograma transesofagico. Medicina (Buenos Aires) 2006; 66: 254-256.

5. MAZOKOPAKIS E, SYROS K, STARAKIS K. Nonbacterial Thrombotic Endocarditis (Marantic Endocarditis) in Cancer Patients. CHDDT. 2010; 10:84-86

6. SALDARRIAGA C, MÚNERA A y DUQUE M. Endocarditis de Libman-Sacks. Rev Colomb Cardiol 2015; 22:144-148.

7. HABIB G, LANCELLOTTI P, ANTUNES M, BONGIORNI M, ET AL. 2015 ESC Guidelines for the management of infective endocarditis. European Heart Journal 2015;36: 3075-3123 